\title{
CLIMATIC FACTORS, REPRODUCTIVE SUCCESS AND POPULATION DYNAMICS IN THE MONTANE VOLE, MICROTUS MONTANUS
}

\author{
Aelita J. Pinter \\ Department of Biological Sciences \\ University of New Orleans \\ New Orleans, LA
}

Objectives

Multiannual fluctuations in population density of small rodents have been known since antiquity. However, factors responsible for this phenomenon remain unknown (Krebs and Myers 1974, Finerty 1980, Taitt and Krebs 1985).

The objectives of this long-term study are to determine whether environmental variables, possibly acting through reproductive responses, contribute to the multiannual fluctuations of the montane vole, Microtus montanus.

\section{Methods}

In 1987 Microtus montanus were livetrapped at two times of the year: the second half of May (spring study period) and mid-July to mid-August (summer study period). Animals were sacrificed as soon as possible after capture. Age estimation for all animals was based on weight, total length, and pelage characteristics. Reproductive organs, the spleen, and the adrenal glands were collected from all animals and preserved in Lillie's buffered neutral formalin for further histological study. Flat skins were also prepared from all animals.

Population density was estimated on the basis of trapping success in a permanent grid (established in 1970). The grid consists of 121 stations, placed $5 \mathrm{~m}$ apart, forming a square, 11 stations (i.e., 50m) on a side. Each station is marked with a stake. Trapping in this grid was carried out only during the summer study period. Unbaited Sherman livetraps, one per station, were set no further than $0.3 \mathrm{~m}$ from each stake. Additional trapping was carried out in nearby meadows. In these areas, however, traps were not set in a regular pattern; rather, they were placed only in locations showing recent vole activity (cuttings, droppings). The purpose of trapping at these additional sites was to obtain additional females for litter size determination, since in years of low density the sample sizes from the grid alone were small.

During the spring study period trapping was carried out in a number of sites, all of them well removed from the permanent grid. The reason for this was to leave populations at the grid site as undisturbed as 
possible since the grid is the major source of information on population density. The main purpose of the spring study period was to determine (on the basis of embryo size) the onset of reproduction on a populationwide basis.

Weather data were obtained from the records of the Moran 5WNW weather station, located less than $2 \mathrm{~km}$ from the study sites. Data on temperature, precipitation and snow accumulation were used to characterize the climatic conditions in the study area on a 12-month basis.

\section{Results}

The onset of reproduction in Microtus montanus in the spring of 1987 was much earlier than usual. All females trapped during the spring study period were either pregnant or lactating. The unusual feature in this observation was that the litters being nursed or gestated were second litters of the year. Usually at the time of the spring study period female Microtus are either not pregnant or are pregnant with their first litter. Another unusual feature in the spring study period was the discovery that some of the females born in the spring of 1987 were already pregnant with their first litter. Litter sizes recorded during the spring study period were unusually large. However, the second litter in M. montanus is significantly larger that the first, both, in the laboratory (Negus and Pinter 1965) as well as in the field (Pinter, unpublished).

By the end of the summer study period the Microtus population had staged a dramatic comeback from the "crash" of the previous year. Indeed, the density attained in 1987 was approximately five times greater than that attained in 1971 (the year that followed the 1970 crash). This dramatic increase in density can be attributed, in part, to the early onset of breeding as well as to the unusually large litter sizes recorded in the summer of 1987. In contrast, during the 1971 recovery, litter sizes were smaller than those in 1987 (Pinter 1986, 1987); reproduction in 1971 also began much later than in 1987.

Weasels (Mustela frenata and M. erminea) in GTNP prey heavily on Microtus. Consequently, it was not surprising that the $1986 \mathrm{crash}$ in vole populations was reflected in the weasel populations of 1987: the number of M. erminea trapped in 1987 was much smaller than that in 1986. The population density of the pocket gopher (Thomomys), however, showed an increase over the 1986 levels.

\section{Conclusions}

The population density of Microtus montanus in 1987 showed a dramatic increase over the extrennely low levels recorded in 1986. This rapid recovery is probably greatly due to the high reproductive success 
(unusually early breeding; large litter sizes). The reproductive success, in turn, appears to be influenced by climatic factors (e.g., early meltoff; record precipitation in July 1987, probably acting through the availability of a component in their diet (Pinter and Negus 1965, Berger et al. 1981).

\section{Acknowledgements}

I gratefully acknowledge the availability of the facilities at the University of Wyoming-National Park Service Research Center without which it would have been difficult to accomplish this work. I am particularly grateful to $\mathrm{Dr}$. Kenneth L. Diem and to the Steering Committee of the UWNPSRC for their obvious cognizance of the fact that an understanding of microtine cycles can be gained only from long-term studies. I also thank David Wallace for assistance with some of the field work.

\section{Literature Cited}

Berger, P. J., N. C. Negus, E. H. Sanders and P. D. Gardner. 1981. Chemical triggering of reproduction in Microtus montanus. Science 195: 575-577.

Finerty, J. P. 1980. The Population Ecology of Cycles in Small Mammals. Mathematic Theory and Biological Fact. Yale Univ. Press, New Haven and London, 234 pp.

Krebs, C. J. and J. H. Myers. 1974. Population cycles in small mammals. Adv. Ecol. Res., 8:267-399.

Negus, N. C. and A. J. Pinter. 1965. Litter sizes of Microtus montanus in the laboratory. J. Mammal., 46:434-437.

Pinter, A. J. and N. C. Negus. 1965. Effects of nutrition and photoperiod on reproductive physiology of Microtus montanus. Amer. J. Physiol., 208:633-638.

Pinter, A. J. 1986. Population dynamics and litter size of the montane vole, Microtus montanus. Can. J. Zool., 64:1487-1490.

Pinter, A. J. 1987. Multiannual fluctuations in precipitation and population dynamics of the montane vole, Microtus montanus. Can. J. Zoology, accepted for publication.

Taitt, M. J. and C. J. Krebs. 1985. Population Dynamics and Cycles. In: Biology of New World Microtus. R. H. Tamarin, ed. Spec. Publ. Amer. Soc. Mammal., pp. 567-620. 